\title{
The Impact of Reading Strategies on EFL Students: A Research Review
}

\section{Yahya Matrouk Al Raqqad ${ }^{1}$, Hanita Hanim Ismail², Kawthar Matrouk Al Raqqad $^{3}$}

\author{
${ }^{1}$ Faculty of Communication and Languages, Universiti Sultan Zainal Abidin , Malaysia \\ yahyaalraggad@gmail.com \\ ${ }^{2}$ Faculty of Communication and Languages, Universiti Sultan Zainal Abidin , Malaysia \\ hanitaismail@unisza.edu.my \\ ${ }^{3}$ Faculty of Social Sciences, Al Balaqa Applied University, Jordan \\ kalraqqad@bau.edu.jo
}

\begin{abstract}
The need to provide appropriate methods of teaching to meet the growing needs of students is increasing as more and more students begin to learn English. This is particularly important for students studying English, who may only be introduced to English in their classroom in a foreign country. Reading strategies have been developed to help learners to resolve language barriers, such as vocabulary and grammar. Teaching reading strategies are proposed as an efficient way of delivering a learning environment that focuses on learners to promote learner independence and develop their language skills. Thirteen research studies were synthesized by means of a Mixed Methods Research Synthesis that collects qualitative and quantitative data, then analyzes them using both qualitative and quantitative approaches. The findings suggest that the evidence does not demonstrate that reading strategies are an effective means for EFL students to improve their comprehension of reading, but it is still uncertain whether certain strategies are better than others. As the results do not provide a particular conclusion on the efficacy of reading strategies, it is concluded that it cannot be helpful to language skills growth by using available class time to teach readings strategies.
\end{abstract}

Keywords-Reading, EFL, Reading Strategies, Mixed Research, Synthesis.

\section{INTRODUCTION}

Reading is important because, through print and digital print format, it enables access to information and knowledge through a condensed medium and is therefore considered to be the main achievement ability for education (Ghahari \& Basanjideh, 2017; Meniado, 2016; Nafmani, 2015). These also refer to students of English who need to have adequate reading skills in many situations, to enroll in higher education, whether in an English-speaking country (ESL) or in a country in which English is a foreign language (EFL) reading is considered a valuable resource for the development of English. However, the reading of many ELLs, especially EFL students with limited sources of information, remains problematic.

Modern definition of reading views reading as a phase in which the learner who brings prior knowledge to the text creates meaning. Such prior knowledge can consist of their comprehension of the language and how the text is used or their awareness of the subject covered. The latter kind of awareness helps the reader to learn details about text and interpret the texts; the former enables the reader to recognize terms in a syntactic structure and to process context based on order. The problems facing EFL students with reading comprehension are directly linked to these two forms of knowledge, for many theories and researchers, and some claim that the problem is a lack of reading skills while others think that languages are not the main problem (McDonough, 1995).

Clarke (1978) put forward theory of the "short circuit" of the method of the good reader[ used to read effectively in its first language] in a second language without language commands and contributed to a return to poor reader strategies" (p.138). The other theory states that, in the presence of difficult text, readers require strategies that adapt to the very different constraints of literary materials ("Reader"), and those reading strategies are required in the face of challenging texts. The 
use of reading strategies by the learners of language will help them overcome language barriers, become more conscious of the comprehension and learning method of the language and develop confidence in learning reading which has a low level of exposure to English outside the classroom. Reading strategies offer a way to do this, and the guidance on reading approaches should be included in the curriculums for English.

As there are many reading approaches, an emphasis should be put on the most important reading strategies if they can be established to use teaching strategies at all times. The EFL context has based recent research on reading strategies. Such researchers have used a variety of techniques in performing their study and evaluations, including guidelines for thinkaloud, where participants must either verbalize or report their reading experience and what strategies they use. Questionnaires about the strategies used and the extent at which they are used, the level of use; experimental and quasiexperimental research that provides guidance on reading strategies and compares the pre and post-test reading test (RCT) scores and interviews.

\section{THE STUDY QUESTION}

The purpose of this current study is to synthesize available research on reading strategies carried out in an EFL context which is most effective in understanding reading. The question to be answered is as follows:

- Are reading strategies effective in enhancing reading comprehension for EFL students?

\section{READING AND READING COMPREHENSION}

It is necessary to comprehend some general ideas on reading to understand the place of reading strategies in an EFL context .There are two different views of reading here which can explain the theoretical divergences. Firstly, the Simple Reading View (SVR), in which reading is paired with two different elements: decode and linguistic comprehension (Hoover \& Gough, 1990, p.128). Decoding requires phonological and spelling comprehension (Silverman, Speece, \& Harring, 2013, p.108). Linguistic comprehension relates to the derivation of concepts on the basis of definitions of sentences, words, and/or whole texts (Hoover \& Gough, 1990, p.131). SVR maintains that both of these are necessary, but not sufficient on their own to be readable.

The interpretation of a text requires that awareness of vocabulary and syntax. Therefore, the student is receiving information passively from a text in this model;' context resides in the text itself, and the reader seeks to replicate the importance' (Dole et al., 1991, p. 240). The meaning of a text would be apparent if a reader could recognize the text words and can examine the grammar of a text. One way of looking at the text from this view is by giving "priority to the text and sections of the text with a variety of emphasis on the form alone or the relation of form and meaning" (Wallace, 2001, p.21). In this regard, it is essential to know vocabulary and grammar to understand what a writer is trying to discuss.

The distinction between strategies and skills has been significant. For Oxford, "ability, skill or knowledge are slowly acquired during language development" (1990, p.6). This indicates that a language student's ability is acquired by practice and experience. Strategies are behavior that the language learner carries out. In fact, language learning is performed consciously and, at least in some way, that means that the language learners are conscious when they use it.

The second feature of learning strategies is that they lead to the completion of a task or goal in the short or long term. The Oxford definition also acknowledges learner and context variation, which ensures that they are not to be seen as a unique solution. Another important characteristic of learning strategies is their capacity to be taught. It means they can be defined and shown how and when they can be used. The goal of learning strategies for L2 students is to "help build the autonomy of the students that need their own learning to be managed consciously" (Hsiao \& Oxford 2002, p. 369).

When these characteristics are used in reading strategies, we can shorten the definition: reading strategies are actions intentionally done to achieve a specific purpose or goal, which can be used in different ways according to context and learner. It should be remembered that these activities can take place before reading, during the reading or after a reading process as is shown in the discussion of the various reading strategies.

\section{CLASSIFICATION OF READING STRATEGIES}

Another point of controversy among field experts is classification. In the past few decades, a variety of frameworks have been established, including numerous similarities between the strategies described. The Oxford framework (1990) and the O'Malley and Chamot framework (1990) are two commonly used classifications that overlap.

The O'Malley and Chamot Framework (OMCF) uses three categories to categorize strategies in their context: cognitive strategies, metacognitive strategies, and emotional and/or affective strategies. Cognitive strategies include those that specifically influence and improve learning on incoming 
information (1990, p. 40). For example, summarizing and repeating information (re-reading) would be included in this category.

Metacognitive techniques are the next category .Both approaches concentrate on the relationship between the learner and the text and include analysis and evaluation strategies. Readers ' comprehension of the text is most frequently mentioned in the sense of reading, monitoring and evaluation (1990, p.44), e.g. when comprehension breaks down (monitoring) and when their strategy uses and their reading results improve (evaluation). The final category is social / affective in relation to the engagement of others with respect to the teaching task or the focus on the mental condition, to "ensure that a learning activity is effective or to reduce anxiety" (1990).

The Oxford Framework (hereafter OXF) classifies learning strategies differently from OMCF, although the meanings of the strategies themselves have many differences. As one thing, OXF splits social / affective approaches into two different categories, which require different motivations and procedures. Two other categories are added: memory strategies and compensation strategies.

Memory strategies apply to techniques that help to make connections so that memory can be mentally processed for a longer time (1990, p.38-39). Semantic mapping and grouping together are included in this category. Compensation strategies are used to assist students in bridging gaps in knowledge such as lack of vocabulary or insufficient grammar (1990: 47). Learners who face unfamiliar vocabulary can use contextual cues for their reading assignments to understand words or to use the dictionary to find meanings.

\section{READING STRATEGIES RESEARCH}

More recently, research concentrate on the impact of reading strategy instructions and the frequency and form of reading strategies used by English language teachers during the reading process and how they are established (Akkakoson \& Setobol 2009; Aghaie \& Zhang 2012; Dhieb-Henia 2003).

In Akkakoson and Setabol's (2009) study, reading strategies instruction was performed over 15 weeks with 207 Thai EFL engineering and science undergraduates in which forty-four reading strategies were taught. Post-test scores for each group were found to have increased significantly. The conclusion is that reading strategy instruction is an efficient way to teach EFL readers in contrast with conventional Thai teaching style, which is' only based on the bottom-up model, because[ Thai teachers] believe that it is important to understand that the alphabets, the words , and the phrases are decoded hierarchically (Akkakoson \& Setabol, 2009, p.331). Two important results of the study showed that the number of participants reported using read strategies was not that after the reading strategies and those strategies for bottom-up processing were typically the highest frequency of reading strategies recorded after instruction.

Dhieb-Henia (2003) conducted the study in which an experimental group of 35 participants received lessons on reading strategies for ten weeks, while 27 others did not receive instructions on reading strategies at the same time. Participants were two universities in Tunisia undergraduate students in biology at EFL. The instruction on reading strategies was "to increase students ' knowledge of the research articles and to encourage them to read research papers as the key means of communication between biologists" (Dhieb-Henia 2003: 395). It has been found that post-test scores for the experimental group have increased significantly. Retrospective interviews found that the participants ' remarks about a short time before and after the instruction process showed a significant difference of (30) comments about inadequate pre-school time and insufficient post-school time). The use of the top-down method after instruction has been increased, but the author has not expressly stated clear reading strategies. It has been concluded that reading strategy instruction has a positive impact on the performance of research papers by students and can be an effective method of teaching compared to the traditional approach that only uses reading texts for extra vocabulary and grammar practice' (2003, p.395).

Aghaie and Zhang (2012) analyzed the effect of reading strategy instruction on a population using an approach to the study of O'Malley and Chamot (1996) and concluded that there was no reading strategy instruction on the comparison. The 80 participants were students of EFL in Iran. The guidance on reading strategies included cognitive and metacognitive CALLA reading strategies. The post-test scores for the treatment group were found to be significantly higher.

There were no findings for the comparison group .Researchers found that metacognitive reading strategies were moved by the treatment group from L2 (English) to L1 (Persian). On the other hand, the comparison group appeared to shift cognitive reading approaches from $\mathrm{L} 2$ reading to $\mathrm{L} 1$. It was concluded that there was a strong association between instruction in reading strategies and progress in reading 
comprehension and that students should be specifically taught in language classrooms reading strategies.

In Nalliveettil's study (2014) 52 first-year engineering students from eleven engineering colleges across India participated in this study. Data collection methods included a qualitative and oral response to comprehension questions about a semi-technical IT journal text and the use of TAPs. Qualitative analysis of the TAP transcripts revealed that (1) successful and sometimes poor readers could learn the meaning of complicated phrases without each word recognizing, and (2) successful readers could use textual features to help with their meaning when understanding is interrupted.; (3) Successful readers ' listed new English words by associating their sounds with a letter cluster that gave rise to faster and more effective word recognition' (Nalliveettil, 2014, p.47); (4) successful readers used background information to assist in obtaining the meaning of the word; It was concluded that English teachers need more instruction in class with the goal of improving students ' reading skills.

Forty non-English students from a first-year engineering college in China engaged in a study by Yang (2016). Descriptive statistics show that (1) the average use of reading strategies is medium and that cognitive strategies were more than metacognitive strategies; (2) the metacognitive approach being used the most frequently mentioned is self-awareness, which is considered to be important for developing reading skills.; and (4) A successful student uses more than the unsuccessful students reading strategies It was suggested that reading strategies should become a part of the teaching practice so that students ' allow them to develop good practices of the intentional use of these methods in their reading process' (Yang, 2016, p.209). The findings from this research are that the instruction of reading strategies seems to improve the comprehension of reading.

\section{METHODOLOGY}

Mixed Method Research Synthesis (MMRS) was used to answer the research question on the effectiveness of reading strategies. The MMRS is best defined as' a synthesis, in order to include, for a broad purpose of interpretation and corroboration, of qualitative, quantitative and mixed technique studies by researchers and a mixed process approach to combine these studies ' (Heyvaerte, Maes, et Onghena, 2013, p.662).

\section{RESEARCH DESIGN}

The design of this study is A - Qual + Quan. This means that in each step of current research the researcher included both qualitative and quantitative data; all qualitative and quantitative methods have been carried out concurrently, giving either approach equal status superiority (Heyvaert et al., 2013, p. 666).

\section{DATA ANALYSIS}

Results were analyzed by comparing the mean scores of each group for reader's pre and post-test comprehension tests for interventionist research which has both experimental and control group studies. Another level of study, including the effect sizes statistic significance and correlation, for the pre-and post-test reader comprehension test scores for the experimental groups, was given.

While statistical significance provides a measure of the increase or decrease in ratings,' an effect size refers to the magnitude of an effect' (Aarts, van den Akker, \& Winkens, 2014, p.62) and offers a more accurate figure by including the sample size in its calculations. The researcher used Cohen's $d$ on each analysis to measure the effect sizes of the change from pre-to post-test scores as the sample sizes were the same. An additional measure was used to assess the correlation (r). This data analysis approach is popular in quantitative primary studies and meta-analysis and is within Heyvaert, et al. (2013)'s proposed framework.

\section{RESULTS}

The current study's review was to examine the influence of reading strategies on reading comprehension in order to answer the research question: are reading strategies effective in improving reading comprehension for EFL students in higher education? Four studies were defined for this part of the study, which included a measure of reading comprehension with the participants before and after reading strategies. Of these studies, three compared the reading comprehension test results among experimental groups (EG), which provided guidance on reading strategies for the interpretation test results of control groups (CG), which were not instructed in reading comprehension strategies. The second study used only the students who obtained lessons from reading strategies and compared the results of reading tests between highly qualified, mid-skilled and low-skilled pupils. 
Table 1. Comparison of Pre-Test and Post-Test RCT Scores for All Groups

\begin{tabular}{|c|c|c|c|c|c|c|c|c|c|}
\hline Study & \multicolumn{2}{|c|}{$\begin{array}{l}\text { Akkakoson } \\
\text { (2013) }\end{array}$} & \multicolumn{2}{|c|}{$\begin{array}{l}\text { Al-Ghazo } \\
\text { (2016) }\end{array}$} & \multicolumn{2}{|c|}{$\begin{array}{l}\text { Habibian } \\
\text { (2015) }\end{array}$} & \multicolumn{3}{|c|}{$\begin{array}{l}\text { Wichadee } \\
\text { (2011) }\end{array}$} \\
\hline Participants & \multicolumn{2}{|l|}{164} & \multicolumn{2}{|l|}{60} & \multicolumn{2}{|l|}{48} & \multicolumn{3}{|l|}{40} \\
\hline Location & \multicolumn{2}{|c|}{ Thailand } & \multicolumn{2}{|c|}{ Jordan } & \multicolumn{2}{|c|}{ Malaysia } & \multicolumn{3}{|c|}{ Thailand } \\
\hline Comparison & \multicolumn{2}{|c|}{$\begin{array}{l}\text { CG \& EG; } \\
\text { HPR, MPR, } \\
\text { LPR (EG). }\end{array}$} & \multicolumn{2}{|c|}{ CG \& EG } & \multicolumn{2}{|c|}{ CG \& EG } & \multicolumn{3}{|c|}{ HPR, MPR, LPR } \\
\hline Pre-Test & $\underline{\mathrm{EG}}$ & $\underline{\mathrm{CG}}$ & $\underline{\mathrm{EG}}$ & $\underline{\mathrm{CG}}$ & $\underline{\mathrm{EG}}$ & $\underline{\mathrm{CG}}$ & $\underline{\mathrm{HPR}}$ & MPR & LPR \\
\hline Mean Score & 30.11 & 29.02 & 38.15 & 37.59 & 10.27 & 9.66 & 19.58 & 13.93 & 8.77 \\
\hline Post-Test & EG: & CG: & $\underline{E G}$ & $\underline{\mathrm{CG}}$ & $\underline{\mathrm{EG}}$ & $\underline{\mathrm{CG}}$ & $\underline{\mathrm{HPR}}$ & MPR & LPR \\
\hline Mean Score & 33.04 & 27.55 & 54.66 & 41.45 & 14.02 & 9.42 & 23.42 & 18.13 & 13.54 \\
\hline
\end{tabular}

The results of studies comparing both of a study group and a control group indicated that in the post-test comprehension test the experimental group has better performance than the control group. In addition, the post-test readings of the groups provided reading strategies indicate an improved test performance compared with pre-test reading comprehension measures. Although in each of the test groups either their post-test results increased slightly in comparison to the previous test (Al Ghazo, 2016) or the post-test reading comprehension test results actually declined. (Akkakoson, 2013; Habibian, 2015).

All the studies including Wichadee (2011) indicate that the average reading comprehension test scores for the groups receiving instruction on reading strategies improved in the post-tests. Wichadee (2011) found that their post-test reading comprehension test results improved at each level The effect size was determined by comparing the results from the pretest and post-test with the mean pooled standard deviation (Table 2 below). Using the pre- and post-test interpretations suggested by Plonsky and Oswald (2014), who criticized the Cohen scale because it ' underestimates the range of effects usually obtained in L2 study ' (2014, p.889), the effect size indicates that in three of the studies the magnitude of reading strategies instruction on reading comprehension test scores was low (Akkakoson, 2013; Habibian, 2015; Wichadee, 2011), but in Al-Ghazo the magnitude of reading strategies was large.

Table 2. Comparison of Pre-Test and Post-Test RCT Scores for EGs Using Cohen's $d$ and Correlation Coefficient $r^{4}$

\begin{tabular}{llllllll} 
Study & $\boldsymbol{n}$ & Test & Mean & S.D. & Pooled S.D. & $\boldsymbol{d}$ & $\boldsymbol{r}$ \\
Akkakoson (2013) & 82 & Pre-Test & 30.11 & 7.12 & 8.32 & 0.352 & 0.1 \\
\cline { 2 - 8 } & & Post-Test & 33.04 & 9.37 & & & \\
Al-Ghazo (2016) & \multirow{2}{*}{30} & Pre-Test & 38.15 & 3.94 & 3.82 & 4.32 & 0.9 \\
& & Post-Test & 54.66 & 3.70 & & & \\
Habibian (2015) & \multirow{2}{*}{24} & Pre-Test & 10.27 & 3.66 & 3.57 & \multirow{2}{*}{1.05} & 0.4 \\
& & Post-Test & 14.02 & 3.47 & & & \\
Wichadee (2011) & \multirow{2}{*}{40} & Pre-Test & 13.95 & 4.74 & 4.68 & 0.913 & 0.4 \\
& & Post-Test & 18.22 & 4.61 & & &
\end{tabular}

Another calculation has been done for the correlation coefficient. Using Plonsky and Oswald's (2014) recommendation again to interpret the correlation coefficient between reading strategies instruction and that post-test reading comprehension test scores, results suggest a small correlation in Akkakoson (2013), a medium correlation in Habibian (2015) and Wichadee (2011), and a large correlation in Al-Ghazo (2016). Such results show that the reading strategies instruction in general has an effect on reading test scores. Therefore, the use of reading strategies can be concluded with an effect on reading comprehension. Nevertheless, the result is largely marginal given the size of the effect. Finally, in answer to the first research question, the results indicate that reading strategies may have a very 
positive impact on the comprehension of reading.

\section{DISCUSSION}

With regard to the research question as to whether reading strategies have an effect on reading comprehension, the experimental and quasi-experimental studies showed that the magnitude between the participants ' pre-tests and post-tests in three of the cases was high (Akkakoson, 2013; Habibian, 2015; Wichadee, 2011), while it was large in only one (AlGhazo, 2016). Studies were conducted at 10-16 weeks of instruction in reading strategies. The instructional process provided details about what the strategies are (declarative knowledge), where each strategy is best used in situations (situational knowledge) and how to use each strategy (procedural knowledge). Although each study used different structures for instruction in reading strategies and included different strategies as part of the instruction material, each group's post-test performance improved.

Such findings are consistent with other research that have investigated the effect on EFL students ' reading comprehension of reading strategies (Aghaie \& Zhang, i2012; Akkakoson \& Setobol, i2009; Cubukcu, 2008; DhiebHenia, 2003; Rasekh \& Ranjbary, 2003; Razi \& Cubukcu, 2014; Whankhom, Phusawisot, \& Sayankena, i2016). Further, for the studies in which participants were part of either a CG or EG (Akkakoson, 2013; Al- Ghazo, 2016; Habibian, i2015). There was an even greater difference between the comprehension scores of the two groups after the study. The use of reading strategies could be an interpretation of these results to assist readers in reading the text. Thus EGs, who taught read strategy specifically and thus acquired declarative, situational and procedural information, could use read strategy to increase their readability.

While evidence from experimental and quasi-experimental studies indicates that reading strategies are successful in improving reading comprehension, there may be other possibilities for higher post-test scores for groups that have been instructed on reading strategies. First of all, it should be noted that only one of the studies showed an increase in posttest scores for CGs that did not receive instruction on reading strategies in the experimental studies (Al- Ghazo, 2016). The remaining studies (Akkakoson, 2013; Habibian, 2015) showed a decrease in CG comprehension after experiments. Similar studies also show an important, but not significant, rise in CGs post-test scores (Cubukcu, 2008; Dhieb-Henia, 2003; Razi \& Cubukcu, 2014). Studies in which the CG provided English instruction would be required that An increase in post-test comprehension would have been made, as the participants would have taken lessons to draw on their understanding of the use of the English language, and Razi and the Cubukcu word "the learning effect" (2014, p.292). This was not the case, though, and it raises questions as to why.

\section{CONCLUSION}

The aim of such a synthesis was to analyze whether sufficient evidence was available to support the teaching of reading strategies using classroom time, which is particularly valuable to EFL Students due to the lack of English-language exposure. The results of the research appear to show that at this point, there is not sufficient evidence to justify the use of class time to teach reading strategies that provide declarative, situational and procedural details about each reading strategy. Of the four studies, which included a training period, only one study showed a large-scale effect (AlGhazo, 2016). The CALLA System developed by O'Malley and Chamot (1996) was used in this particular survey and could be proof for its effectiveness. Nevertheless, this cannot be concluded with any certainty due to limited research into its application in an EFL context.

\section{REFERENCES}

[1] Aarts, S., van den Akker, M., and Winkens, B. (2014). The Importance of Effect Sizes, European Journal of General Practice, 20(1), 61-64.

[2] Aghaie, R., and Zhang, L.J. (2012). Effects of Explicit Instruction in Cognitive and Metacognitive Reading Strategies on Iranian EFL Students' Reading Performance and Strategy Transfer, Instructional Science, 40(6), 10631081.

[3] Akkakoson, S. (2013). The Relationship between Strategic Reading Instruction, Student Learning of L2-based Reading Strategies and L2 Reading Achievement, Journal of Research in Reading, 36(4), 422-450.

[4] Akkakoson, S., and Setobol, B. (2009). Thai EFL Students' Use of Strategies in Reading English Texts, The Journal of KMUTBN, 19(3), 329-342.

[5] Al-Ghazo, A. (2016). The Effect of Explicit Instruction of Meta Cognitive Learning Strategies on Promoting Jordanian Language Learners' Reading Competence, Journal of Education and Practice, 7(10), 170-177.

[6] Chamot, A.U., and O'Malley, J.M. (1996). The Cognitive Academic Language (18) Learning Approach: A Model for Linguistically Diverse Classrooms, The Elementary School Journal, 96(3), 259-273. 
[7] Clarke, M.A. (1978). Reading in Spanish and English: Evidence from Adult ESL Students, Language Learning, 29(1), 121-150.

[8] Cubukcu, F. (2008). Enhancing Vocabulary Development and Reading Comprehension Through Metacognitive Strategies, Issues in Educational Research, 18(1), 1-11.

[9] Dhieb-Henia, N. (2003). Evaluating the Effectiveness of Metacognitive Strategy Training for Reading Research Articles in an ESP Context, English for Specific Purposes, 22, 387-417.

[10] Dole, J.A., Duffy, G.G., Roehler, L.R., and Pearson, P.D. (1991). Moving from the Old to the New: Research on Reading Comprehension Instruction, Review of Educational Research, 61(2), 239-264.

[11] Ghahari, S., and Basanjideh, M. (2017). Psycho-linguistic Model of Reading Strategies Awareness in EFL Contexts, Reading Psychology, 38(2), 125-153.

[12] Heyvaert, M., Maes, B., and Onghena, P. (2013). Mixed Methods Research Synthesis: Definition, Framework, and Potential, Quality and Quantity, 47(2), 659-676.

[13] Hoover, W.A., and Gough, P.B. (1990). The Simple View of Reading, Reading and Writing, 2, 127-160.

[14] Hsiao, T., and Oxford, R.L. (2002). Comparing Theories of Language Learning Strategies: A Confirmatory Factor Analysis, The Modern Language Journal, 86(3), 368-383.

[15] McDonough, S.H. (1995). Strategy and Skill in Learning a Foreign Language. London: Edward Arnold.

[16] Meniado, J.C. (2016). Metacognitive Reading Strategies, and Reading Comprehension Performance of Saudi EFL Students, English Language Teaching, 9(3), 117-129.

[17] Nalliveettil, G.M. (2014). Assessing Reading Strategies of Engineering Students: Think Aloud Approach, English Language Teaching, 7(5), 38-49.

[18] O’Malley, J.M., and Chamot, A.U. (1990). Learning Strategies in Second Language Acquisition, Cambridge: Cambridge University Press.

[19] Plonsky, L., and Oswald, F.L. (2014). How Big is "Big"? Interpreting Effect Sizes in L2 Research, Language Learning, 64(4), 878-912.

[20] Silverman, R.D., Speece, D.L., and Haring, J.R. (2013). Fluency Has a Role in the Simple View of Reading, Scientific Studies of Reading, 17(2), 108-133.

[21] Wichadee, S. (2011). The Effects of Metacognitive Strategy Instruction on EFL Thai Students' Reading Comprehension Ability, Journal of College Teaching and Learning, 8(5), 31-40. 